\title{
Editorial
}

\section{The fall of strategic planning}

In 1994, Henry Mintzberg wrote on "The Rise and Fall of Strategic Planning" [1], with the emphasis on the "fall" rather than the "rise". Similarly, Robert $H$. Hayes has increasingly wondered why there had to be such a precipitous loss of US competitiveness during the heydays of strategic planning. And why are there such strong signs of competitive renewal after the decline of strategy? To top it all off, Michael E. Porter feels compelled - at the end of 1996 - to write an article entitled "What Is Strategy?" [2]. Does not every MBA know by now?

Also Mintzberg's book starts with "What Is Planning Anyway?" and Hayes argues that most strategic practitioners and theorists got the notion of strategy all wrong, "the other way around". Clearly something is amiss: either the practitioners cannot keep up with theorists' frequent changes of heart or the theorists still cannot decipher the practice.

Were the many decades of vigorous development of strategic planning theories and practices wasted? Does anybody at least know what strategy, strategic planning or strategic management are? If yes, where do these urges and didactical fervor to explain even most fundamental linguistic labels spring from?

The problem is that a generation of researchers and practitioners take strategic planning for granted, rarely asking what is it or what is it good for, happily doing research, establishing departments and even granting degrees. The three authors mentioned above, all prominent in the field of strategy, are asking questions which the "soldiers" of the field are afraid even to imagine. This is not uncommon: the leaders are bound to have more critical minds than their followers - that is why they achieved their positions of leadership in the first place.

Most of the defenders of strategic planning appear to be fighting to keep their respect: jobs, positions or theories. Strategic planning departments are still rather well populated, Porter does not like to see his idea of "strategic positioning" going wayward. But Mintzberg and Hayes appear to see clearly the end and the demise of planning, forecasting and strategy "as we know it".
Undoubtedly, the paradigm of strategic planning seems to be at least shifting. The culprits of the shift are global competition, flexibility, dynamic responsiveness and new technologies. No static "positioning" would do in such a rapidly changing environment.

The declining role of traditional forecasting is well known [4] and not too surprising in an unstable and less predictable business environment. It is therefore normal to expect that also the traditional corporate and strategic planning are to be affected rather significantly. Instead of forming goals based on predicting the future environment, and then mobilizing the ways and resources for reaching them, the process of strategy formation is increasingly being reversed by practice.

First, one enhances current processes and resources into core competencies. Then one formulates the goals for the most effective utilization and further enhancement of these competencies for satisfying the customer. Instead of the (goals $\rightarrow$ ways $\rightarrow$ resources) dogma-sequence of forecasting-based strategy, modern and flexible corporations are exploiting the (resources $\rightarrow$ ways $\rightarrow$ goals) sequences of strategy formation, rooted more firmly in organizational abilities, competencies and knowledge, not in increasingly blurred and expensive dreams of stability and predictability.

In the era of increased need for flexibility and responsiveness, global competitors can and do copy any market "position" or static competitive advantage rather quickly. The advantages derived from static positioning can therefore be only temporary. Is it wise to invest in and solidify with something that cannot last and is easy to emulate?

What can companies do in this environment of "quick copy"? Do they mutually annihilate each other? Do they engage in hypercompetition or "mutually destructive competition" [2]? No.

Such companies engage in forming long-term strategic alliances and organizational networks - they collaborate. In order to collaborate effectively, they 
have to become flexible so that they can effectively complement their partners. Their best bet in facing their partners, suppliers and customers is to move beyond operational effectiveness towards dynamic core competencies, flexibility and - knowledge.

Building up organizational knowledge - the corporate ability to coordinate action well - is the new strategy. Knowledge is inexhaustible, it can be continually renewed and expanded, its copying is a form of flattery and provides competitive stimulation. Knowledge acquisition is not easy and is always special and individual.

There are many businessmen and managers who increasingly fail - to the consternation of strategy gurus - to distinguish between operational effectiveness and strategy. Porter believes that operational effectiveness (including efficiency) is related to performing similar activities better, while strategic positioning means performing similar activities differently or performing different activities. People do fail to distinguish between the two because there are no processes of operations and goals or objectives figuring prominently in such distinction. The two postures can be both strategic and operational, depending on the goals.

Pursuing both operational efficiency and effectiveness could be at the core of creating competitive advantage, as can be the pursuit of radical reengineering of processes and their operations. The goals must be an integral part of any strategy formation, whether they enter a priori or ex post. Discussing business strategy without even mentioning goals or processes is a strange exercise.

The reality is a bit more complex. Vis-à-vis their competition, companies can perform the same processes and activities in order to attain the same goals, but do it more cheaply, faster, more reliably - simply better. That is operational efficiency. Other companies could aim for the same goals, but perform their processes and operations in different ways in order to achieve their goals more effectively. That is operational effectiveness. This strategy is best exemplified by the reengineering of business processes and operations (BPR). Many companies are also engaging the same processes and operations (core competencies) to dynamic pursuits of different, frequently changing goals. They engage in strategy formation, moving beyond the efficiency of effectiveness of operational pursuits. Yet other companies have found it quite beneficial to perform different processes and operations in order to attain different goals. That is strategic reengineering.
Table 1

Classification of competitive strategic postures

\begin{tabular}{llll}
\hline \multirow{2}{*}{ Means } & & \multicolumn{2}{c}{ Goals } \\
\cline { 3 - 4 } & Same & Efficiency & $\begin{array}{l}\text { Strategy } \\
\text { formation }\end{array}$ \\
\hline & Different & $\begin{array}{l}\text { Effectiveness } \\
(\mathrm{BPR})\end{array}$ & $\begin{array}{l}\text { Strategic } \\
\text { reengineering }\end{array}$ \\
\hline
\end{tabular}

These four basic strategic postures are summarized in Table 1. Doing the same or similar with respect to means, goals or both, is not sustainable; doing the different, especially with respect to both goals and means, is more difficult to copy and much easier to protect as a competitive advantage.

The crucial point is to understand what is meant by "different". It clearly cannot mean "just different", but must amount to a purposefully created difference in processes and operations (the means) as well as the goals. The differentiation must be derived from customers' needs and preferences. Customers clearly prefer to "have it both ways": cheap and good, fast and cheap, good, fast and cheap, etc. - i.e., with little or no trade-offs among the multiple dimensions of competitive performance.

In fact, customers view these multiple dimensions as integrated packages, with no trade-offs allowed or desirable. It is not perceived as high quality if it comes at very high cost; it is not perceived as cheap if it takes forever; and it cannot be perceived as customer value if it is not cheap, fast and of high quality in relation to the competition. These integrated value packages cannot be disintegrated into trade-offs.

The producers find it easier to deal with trade-offs: they can easily deliver something very cheap, or very fast or of very high quality, but not all of these at the same time. Producers prefer to work in a trade-offbased environment, while customers would prefer to live in a trade-off-free environment.

The producers who come closest to satisfying the customers, by recreating a trade-off-free environment for them, create also the strongest long-term competitive advantage for themselves. How does one build a trade-off-free environment? By doing things differently and by doing different things - all in the direction and for the purpose of trade-off elimination [3].

Let us consider traditional productivity frontier, comparing nonprice buyer value delivered and relative cost position [2], as in Fig. 1. The frontier describes the maximum value that a company can deliver at a given cost under the best currently available 


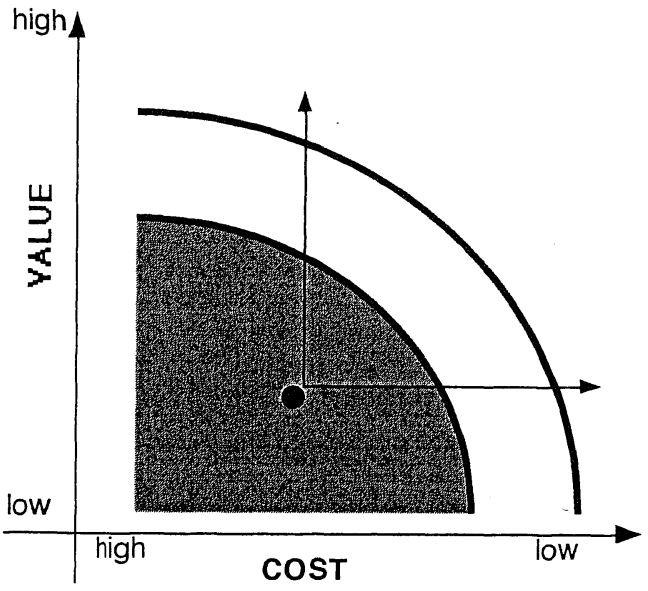

Fig. 1. Trade-off-based improvement.

circumstances. Observe that only companies operating below the productivity frontier are in a trade-offfree environment and can improve by moving towards the frontier. Once on the frontier, such companies can only trade off value against cost, by moving laterally along the frontier, back and forth.

As the productivity frontier shifts outward (due to technological improvements), the companies scramble again for a temporarily trade-off-free environment, only to see their "advantage" quickly dissipated as competitors copy each other and are forced to face the customer-unfriendly trade-offs again.

The situation in Fig. 1 is loaded with assumptions. The trade-offs between value and cost are assumed to exist a priori, in the very way the frontier is drawn. No differentiation of means and goals is present, companies cannot design their own frontiers by engaging in different activities and different ways of carrying them out, etc. This is not the case in the real world.

In Fig. 2 we represent how companies redesign and reengineer their own processes and operations so that the frontier (trade-offs) is eliminated and the tradeoff-free environment can be continually expanded and improved upon. The shaded area (the universe of corporate activities) of Fig. 2 represents a distinct advantage and improvement over the shaded area of Fig. 1. The situation in Fig. 2 is a true, long-term strategic advantage, while the situation in Fig. 1 requires continuous operational improvements and trade-off choices, without fully satisfying the customer.

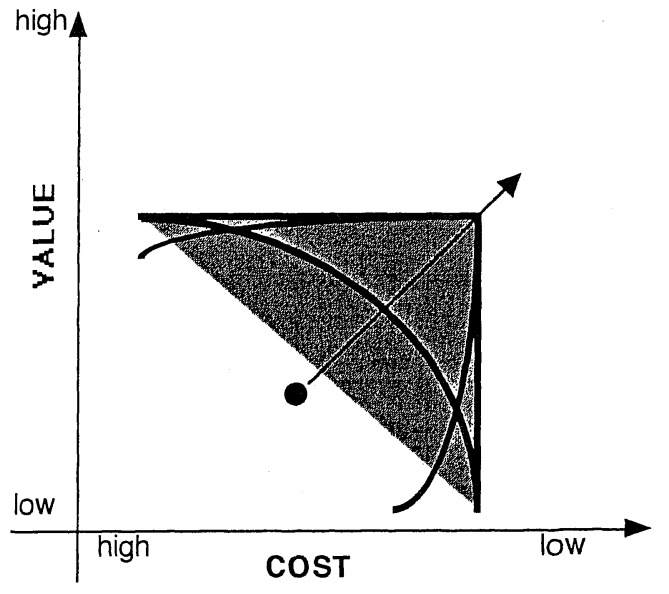

Fig. 2. Trade-off-free improvement.

Strategic reengineering is about creating competitive advantage through choosing different goals and different activities (or the different ways of carrying them out) so that a trade-off-free environment is created or at least approached as closely as possible, delivering a unique mix of value to the customer. Japanese have shown the way in the 1980s by purposefully eliminating the trade-offs between defects and costs. All other types of trade-offs can be similarly eliminated by BPR-oriented companies, capable of doing things differently and doing different things.

Modern strategy is not about making trade-offs i.e., choosing one inferior alternative over another but about creating superior alternatives for the customer and thus for the company.

Milan Zeleny Graduate School of Business Fordham University at Lincoln Center New York City, USA

\section{References}

[1] H. Mintzberg, The Rise and Fall of Strategic Planning, Free Press, New York, 1994.

[2] M.E. Porter, What is strategy?, 'Harvard Business Review, November-December, 1996, 61-78.

[3] M. Zeleny, Towards trade-off-free management, Human Systems Management 13(4) (1994), 241-243.

[4] M. Zeleny, The decline of forecasting?, Human Systems Management 16(1) (1997), 153-155. 